\title{
Microvascular density and endothelial area correlate with Ki-67 proliferative index in surgically-treated pancreatic ductal adenocarcinoma patients
}

\author{
MICHELE AMMENDOLA ${ }^{1,2}$, ROSARIO SACCO ${ }^{1}$, ILARIA MARECH $^{3}$, GIUSEPPE SAMMARCO $^{1}$, \\ VALERIA ZUCCALÀ ${ }^{4}$, MARIA LUPOSELLA ${ }^{5}$, ROSA PATRUNO ${ }^{3}$, MARCELLA GIORDANO $^{1}$, \\ EUSTACHIO RUGGIERI ${ }^{2}$, NICOLA ZIZZO ${ }^{6}$, COSMO DAMIANO GADALETA $^{3}$ and GIROLAMO RANIERI ${ }^{3}$
}

\footnotetext{
${ }^{1}$ Department of Medical and Surgery Science, Clinical Surgery Unit, University of Catanzaro 'Magna Graecia' Medical School, Catanzaro 88100; ${ }^{2}$ Surgery Unit, National Cancer Research Centre, 'Giovanni Paolo II', Bari 70124;

${ }^{3}$ Diagnostic and Interventional Radiology Unit with Integrated Section of Translational Medical Oncology,

National Cancer Research Centre, 'Giovanni Paolo II', Bari 70124; ${ }^{4}$ Department of Health Science,

Pathology Unit; ${ }^{5}$ Department of Medical and Surgery Science, Cardiovascular Disease Unit,

University of Catanzaro 'Magna Graecia' Medical School, Catanzaro 88100; ${ }^{6}$ Chair of Pathology,

‘Aldo Moro' University of Bari, Bari 70010, Italy
}

Received July 29, 2014; Accepted April 9, 2015

DOI: 10.3892/ol.2015.3286

\begin{abstract}
Previous experimental and clinical data have indicated that tumour cell proliferation is associated with angiogenesis; in addition, an increased microvascular density (MVD) of tumours has been associated with poor prognosis in solid and haematological malignancies. However, limited data exists regarding the association between tumour cell proliferation and angiogenesis in primary tumour tissue from pancreatic ductal adenocarcinoma (PDAC) patients; therefore, the present study aimed to investigate this association. A series of 31 PDAC patients with stage Tumour $(\mathrm{T})_{2-3}$ Node $(N)_{0-1}$ Metastasis $(M)_{0}$ were recruited into the present study and subsequently underwent surgery. PDAC tissue and adjacent normal tissue (ANT), resected during surgery, were evaluated using immunohistochemistry and image analysis methods to determine MVD, endothelial area (EA) and Ki-67 expression, which is an indicator of cell proliferation rate. The results demonstrated a correlation between the above parameters with each other as well as the main clinico-pathological features of PDAC. Significant differences were identified in MVD, EA and Ki-67 proliferation index between PDAC and ANT. It was demonstrated that MVD, EA and Ki-67 prolif-
\end{abstract}

Correspondence to: Dr Girolamo Ranieri, Diagnostic and Interventional Radiology Unit with Integrated Section of Translational Medical Oncology, National Cancer Research Centre, 'Giovanni Paolo II', 65 Via Orazio Flacco, Bari 70124, Italy E-mail: giroran@tiscalinet.it

Key words: angiogenesis, endothelial area, Ki-67 proliferation index, pancreatic ductal adenocarcinoma, adjacent normal tissue eration index were significantly correlated with each other in tumour tissue $(\mathrm{r}=0.69-0.81 ; \mathrm{P}=0.001-0.003)$. However, no other significant correlations were identified. These data therefore suggested that angiogenesis and cell proliferation rate were significantly increased in PDAC compared with ANT, which provides a biological basis for the potential use of novel combinations of angiogenesis inhibitors and anti-proliferative chemotherapeutic drugs in the treatment of PDAC.

\section{Introduction}

Tumour tissue angiogenesis is often evaluated by determining microvascular density (MVD) and endothelial area (EA) (1-3). MVD and EA have been experimentally proposed to be biomarkers associated with biological aggressiveness and clinical outcome in animal and human malignancies. In regards to pancreatic cancer, it has been established that angiogenesis has a role in its development and progression (4-17). In addition, $\mathrm{Ki}-67$ expression is an important parameter for biological aggressiveness and prognosis in tumour tissue; $\mathrm{Ki}-67$ antigens are initially expressed in S-phase and increase throughout S- and $\mathrm{G}_{2}$-phase until they reach their peak expression during mitosis. Following division, cells progress into $\mathrm{G}_{1}$-phase with high levels of Ki-67 antigen, which gradually decrease during this phase and are low or no longer expressed in cells in prolonged $\mathrm{G}_{1}$. Therefore, $\mathrm{Ki}-67$ protein is expressed in proliferating cells throughout the cell cycle, but not in quiescent $\left(\mathrm{G}_{0}\right)$ cells $(18-20)$. Ki-67 may be used as a proliferation index to characterise proliferating and non-proliferating tumour cells $(21,22)$; however, no data have been reported regarding the correlation between MVD or EA and Ki-67 proliferation index in pancreatic ductal adenocarcinoma (PDAC). 
The aim of the present study was to analyse MVD, EA and $\mathrm{Ki}-67$ expression in proliferating cells in a series of 31 human PDAC tissues and in their corresponding adjacent normal tissue (ANT) in order to evaluate differences in these tissue parameters between normal and malignant tissue. In addition, the present study aimed to evaluate the potential correlation of these factors with each other. Furthermore, the correlation between each analysed tissue index and the primary clinico-pathological features of PDAC were investigated.

\section{Patients and methods}

Patients. The clinico-pathological features of selected patients are summarised in Table I. A total of 31 PDAC patients (PDACPs) underwent potentially curative surgical resection at the Clinical Surgery Unit, University of Catanzaro 'Magna Graecia' Medical School (Catanzaro, Italy). Surgical approaches used included pancreaticoduodenectomy, distal pancreatectomy and total pancreatectomy with lymph node dissection. Tumour tissues and ANT were resected from patients and tumour tissues were staged according to the American Joint Committee on Cancer classification guidelines (7th edition) and the World Health Organization classification guidelines (2000 version) for pathologic grading $(23,24)$. Computed tomography (CT) was conducted on a Somatom Sensation CT scanner (Siemens AG, Munich, Germany) to confirm that all patients did not have distant metastases and ten patients underwent neo-adjuvant therapy with Gemcitabine or Folfirinox prior to surgery. The present study was approved by the Ethics Committee of 'Mater Domini' Hospital, 'Magna Graecia' University (Catanzaro, Italy). Full signed informed consent was obtained from each patient enrolled in the present study, including the authorisation to utilise each tissue sample for experimental studies.

Immunohistochemistry. For the evaluation of MVD, EA and $\mathrm{Ki}-67$ proliferation index in PDAC tissue and ANT, a three-layer biotin-avidin-peroxidase system was utilised, as previously described (25). In brief, $4-\mu \mathrm{m}$ thick serial sections of formalin-fixed and paraffin-embedded tumour samples and the corresponding ANT ( 2 of each sample) were deparaffinised. Formalin and paraffin were purchased from Bio Optica Milano SpA, (Milan, Italy). For antigen retrieval, sections were then microwaved at $500 \mathrm{~W}$ for $10 \mathrm{~min}$; following which, endogenous peroxidase activity was blocked with 3\% hydrogen peroxide solution (Dako, Glostrup, Denmark). Subsequently, adjacent sections were incubated with the mouse monoclonal anti-CD31 antibodies (dilution, 1:40; JC70a; Dako) for $30 \mathrm{~min}$ at room temperature and mouse monoclonal anti-Ki-67 (dilution, 1:100; MIB-1; Immunotech, Inc., Marseilles, France) for $1 \mathrm{~h}$ at room temperature. The bound antibodies were visualised using a biotinylated horse anti-mouse $\operatorname{IgG}(\mathrm{H}+\mathrm{L})$ secondary antibody (dilution, 1:100; BA-2000; Vector Laboratories, Inc., Burlingame, CA, USA) incubated for $1 \mathrm{~h}$ at room temperature, followed by avidin-biotin peroxidase complex and NovaRED (Vector Laboratories, Inc.). Nuclear counterstaining was performed using Gill's haematoxylin no. 2 (Polysciences, Inc., Warrington, PA, USA). For the negative
Table I. Clinico-pathological features of patients.

\begin{tabular}{lc}
\hline Patient characteristics & No. of patients \\
\hline Overall series & 31 \\
Age & \\
$<65$ & 23 \\
$>65$ & 8 \\
Gender & \\
Male & 25 \\
Female & 6 \\
Tumour site & \\
Head & 13 \\
Body-tail & 18 \\
TNM & \\
$\mathrm{T}_{2} \mathrm{~N}_{0-1} \mathrm{M}_{0}$ & 14 \\
$\mathrm{~T}_{3} \mathrm{~N}_{0-1} \mathrm{M}_{0}$ & 17 \\
Histologic type & \\
Ductal adenocarcinomas & 31 \\
Histologic grade & \\
$\mathrm{G} 1-\mathrm{G} 2$ & 19 \\
$\mathrm{G} 3$ & 12
\end{tabular}

TNM were determined by American Joint Committee on Cancer staging classification and histologic type was assessed according to Lauren classification. TNM, tumour, node, metastasis; G, grade.

controls, slides were incubated with secondary antibodies and primary antibody was omitted.

Morphometrical assay. A Quantimet 500 image analysis system (Leica Microsystems GmbH, Wetzlar, Germany) with a connected Nikon Eclipse E400 Biological Microscope (Nikon Corporation, Tokyo, Japan) was employed. The five most vascularised areas ('hot spots') were selected at low magnification and the individual vessels (Fig. 1A) and Ki-67 proliferation index (Fig. 1B and C) were counted at $\mathrm{x} 400$ magnification $\left(0.19 \mathrm{~mm}^{2}\right.$ area) in tumour tissue and ANT. A method of morphometric evaluation was used as described in a previous study (26). Single red-stained endothelial cells, endothelial cell clusters and microvessels, clearly separated from adjacent microvessels, tumour cells, normal epithelial cells and other connective tissue elements were also counted. The immunostained area was evaluated identifying and manually delimiting the perimeter of each red immunostained area in a field of $0.19 \mathrm{~mm}^{2}$ on the computer, then the software calculated the delimited area. In tumour tissue, areas of necrosis were not included in the counting area. Single red-stained endothelial cells were also evaluated in terms of immunostained area at x400 magnification $\left(0.19 \mathrm{~mm}^{2}\right.$ area) (25). Ki-67 expression was determined in corresponding areas to MVD 'hot spots' and only specific red nuclear staining was considered. The number of MIB-1 positively-stained nuclei was counted at x400 magnification $\left(0.19 \mathrm{~mm}^{2}\right.$ area). The fraction of Ki-67-positive cells was calculated as the ratio of positively-stained tumour cells to all tumour cells. Furthermore, morphological detail, including 
Table II. Comparison of MVD, EA and Ki-67-positive cells in PDAC tissue and ANT.

\begin{tabular}{lccc}
\hline Tissue type & $\begin{array}{c}\text { MVD (no. of } \\
\text { microvessels) }\end{array}$ & KA $\left(\mu^{2}\right)$ & $\begin{array}{c}\text { Ki-67 positive fraction (no. of } \\
\text { MIB-1-positive nuclei) }\end{array}$ \\
\hline ANT & $8 \pm 4$ & $73.12 \pm 27.88$ & $15 \pm 6$ \\
PDAC & $27 \pm 8$ & $186.06 \pm 65.89$ & $66 \pm 25$ \\
P-value & 0.001 & 0.003 & 0.001 \\
\hline
\end{tabular}

Values are presented as the mean \pm standard deviation and statistical comparisons were performed using the Student's t-test. Results were counted in highly vascularised 'hot spots' at x400 magnification $\left(0.19 \mathrm{~mm}^{2}\right.$ area; $\left.\mathrm{n}=5\right)$. MVD, microvascular density; EA, endothelial area; ANT, adjacent normal tissue; PDAC, pancreatic ductal adenocarcinoma.
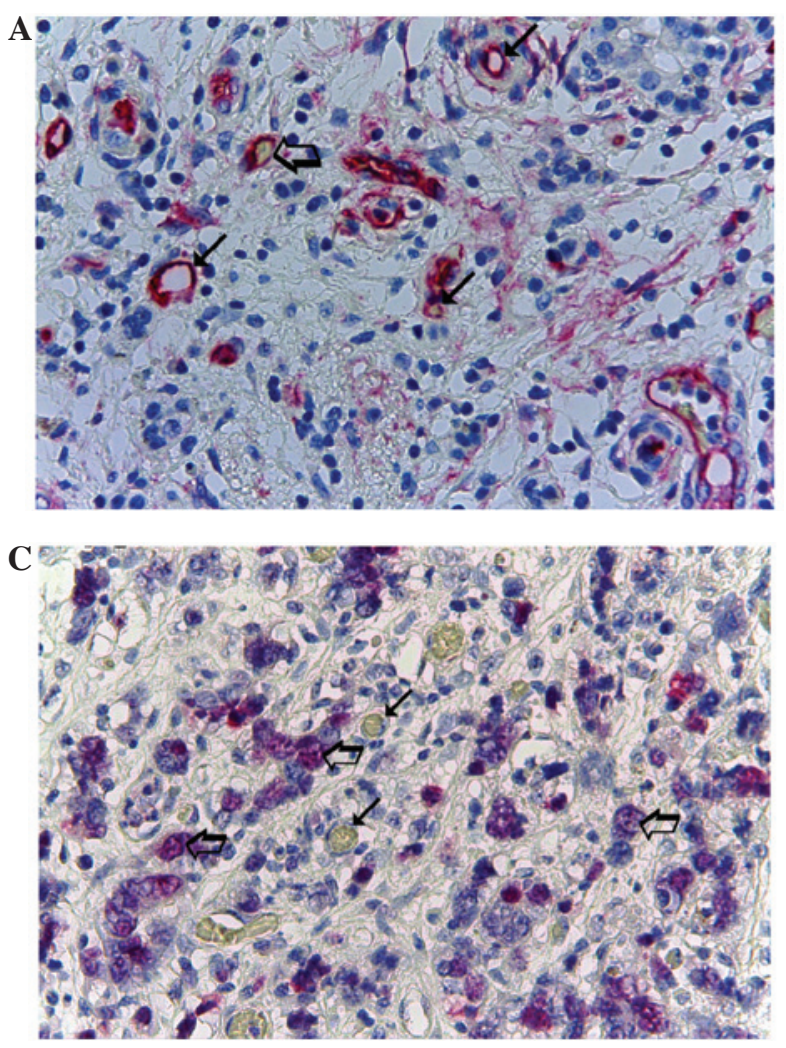

B

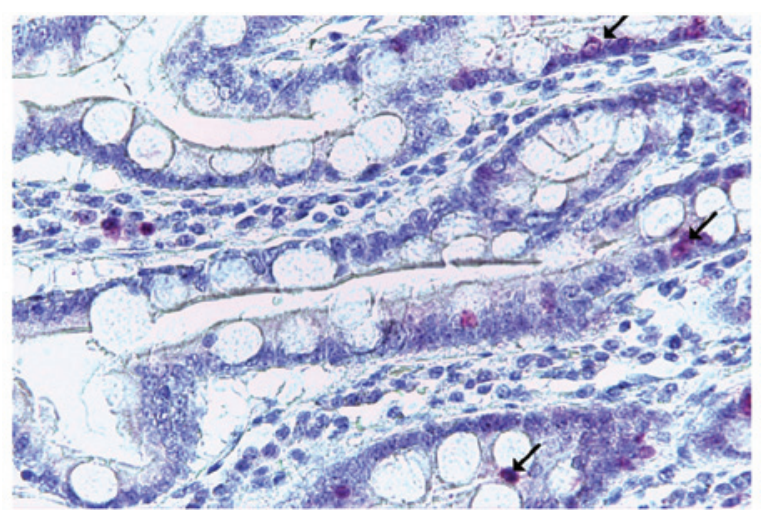

D

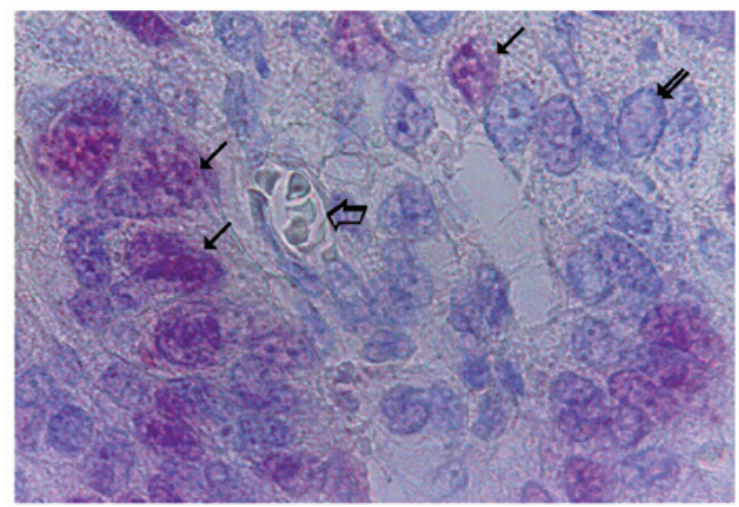

Figure 1. Morphometrical analysis of MVD and Ki-67 proliferation index in PDAC tissue. (A) Highly vascularised pancreatic ductal adenocarcinoma sample stained with anti-CD-31 antibodies. Numerous red immunostained microvessels are visible: Small arrows, microvessels with a visible lumen; large arrow, microvessel with a red blood cell in its lumen, this acted as an internal positive control (magnification, $\mathrm{x} 400$ ). (B) Well-differentiated and (C) poorly-differentiated PDAC samples stained with anti-Ki-67 antibodies; low and high rates of proliferation are observed, respectively. Arrows, single red-stained proliferating nuclei (magnification, x400). (D) Poorly-differentiated PDAC sample stained with anti-Ki-67 antibodies. Small arrows, single red-stained proliferating nuclei; large arrow, microvessel with several red blood cells in its lumen, this acted as an internal positive control. Red proliferating nuclei are visible near the microvessels (magnification, x1,000, in oil). MVD, microvascular density; PDAC, pancreatic ductal adenocarcinoma.

the microvessel, its wall and the red blood cells in the lumen. Notably, the diameter of the lumen was very small compared with the red proliferating nuclei that were clearly visible near the microvessel. This was observed at x1,000 magnification in oil (Fig. 1D).

Statistical analysis. Significant differences in the angiogenic indexes and $\mathrm{Ki}$-67-positive fraction between PDAC and ANT were assessed using the Student's t-test. Linear correlations among MVD, EA and Ki-67 proliferation index were compared with each other and were quantified using the Pearson's correlation coefficient (r). Correlations among the MVD, EA and Ki-67 proliferation index groups and the main clinico-pathological features were analysed using the Chi-square test. Values are presented as the mean \pm standard deviation. $\mathrm{P}<0.05$ was considered to indicate a statistically significant difference between values. All statistical analyses were performed using the SPSS statistical software package, version 20.0 (IBM SPSS, Armonk, NY, USA).

\section{Results}

All the tissue parameters evaluated, including MVD, EA and $\mathrm{Ki}-67$ proliferation index, were compared between PDAC 

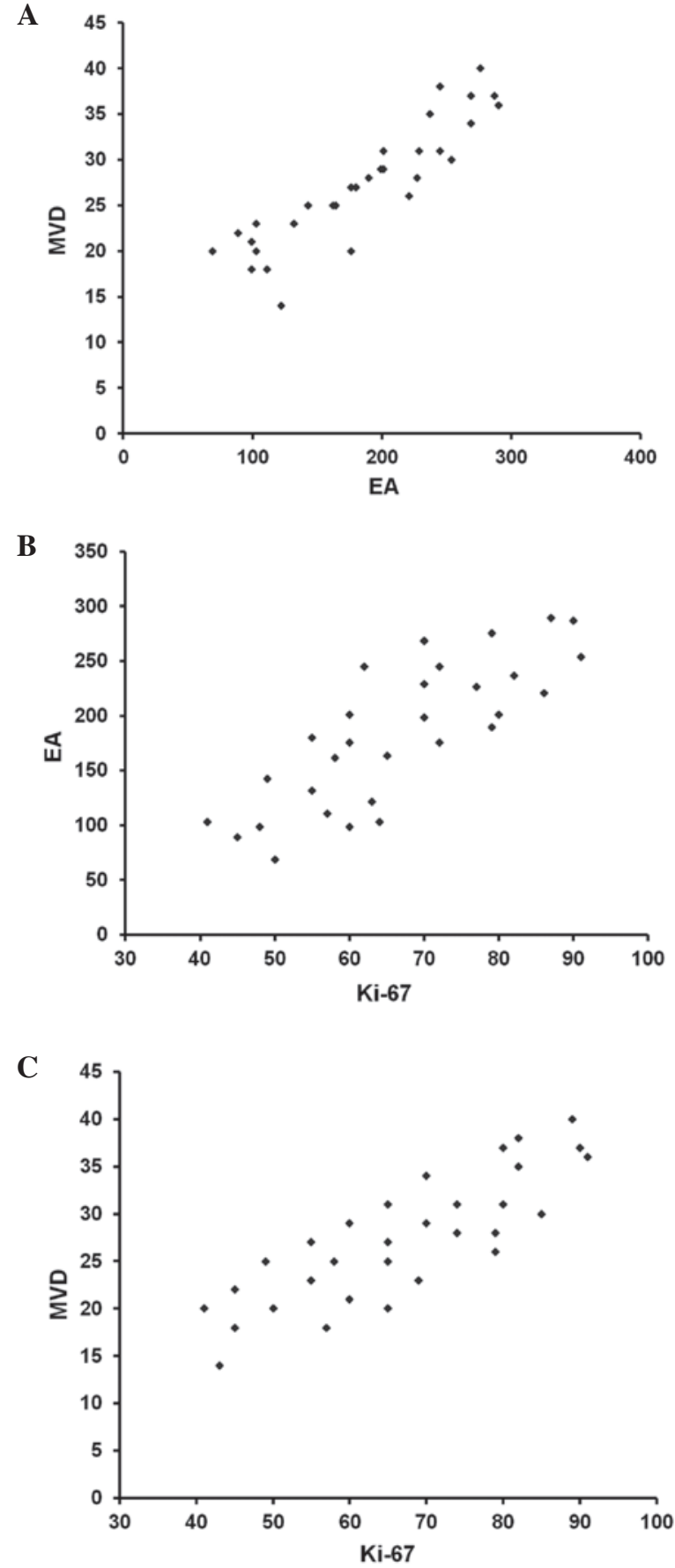

Figure 2. Correlation analysis between MVD, EA and Ki-67 proliferation index in pancreatic ductal adenocarcinoma tissue. (A) MVD and EA ( $\mathrm{r}=0.80$; $\mathrm{P}=0.001) ;(\mathrm{B}) \mathrm{MVD}$ and Ki-67 ( $\mathrm{r}=0.72 ; \mathrm{P}=0.003)$; (C) EA and Ki-67 ( $\mathrm{r}=0.65$; $\mathrm{P}=0.004)$. MVD, microvascular density; EA, endothelial area.

tissue and ANT; the results are reported in Table II. The number of microvessels and EA were significantly higher in PDAC tissue $\left(27 \pm 8\right.$ and $186.06 \pm 65.89 \mu^{2}$, respectively) compared with the corresponding values in ANT ( $8 \pm 4$ and $73.12 \pm 27.88 \mu^{2} ; \mathrm{P}=0.001$ and $\mathrm{P}=0.003$, respectively). In addition, a significantly higher number of Ki-67-positive proliferative cells were observed in PDAC tissue compared with ANT (66 \pm 25 vs. $15 \pm 6 ; \mathrm{P}=0.001)$ (Table II). Immunohistochemical staining was performed using anti-Ki-67 antibodies and the evaluation at x1,000 magnification in oil demonstrated that in highly vascularised cancer tissue, red-immunostained proliferating nuclei were highly expressed and were primarily located in perivascular position (Fig. 1D).

As shown in Fig. 2, in tumour tissue there were significant correlations between MVD and EA ( $\mathrm{r}=0.80 ; \mathrm{P}=0.001)$, between MVD and Ki-67 ( $\mathrm{r}=0.72 ; \mathrm{P}=0.003)$ and between $\mathrm{EA}$ and $\mathrm{Ki}-67(\mathrm{r}=0.65 ; \mathrm{P}=0.004)$. No correlation was detected concerning the parameters MVD, EA or Ki-67 and the main clinico-pathological features of PDAC.

\section{Discussion}

Previous studies have demonstrated that angiogenesis and Ki-67-positive fraction are essential for the development and progression of tumours (27-31). In addition, numerous studies have suggested that increased tissue MVD and Ki-67 proliferation index, which were individually assessed, were correlated with a poor prognosis in PDACP $(21,22)$. However, studies into PDAC are limited and no data have been previously published regarding the correlation between $\mathrm{MVD}, \mathrm{EA}$ angiogenic indexes and $\mathrm{Ki}-67$ fraction in PDAC. The results of the present study demonstrated that MVD, EA and Ki-67 proliferation index were all significantly increased in PDAC tissue compared with ANT; in addition, it was revealed that in tumour tissue, these parameters were increased in parallel to each other. Of note, a close spatial association was observed between proliferating tumour cells and microvessels, as determined using image analysis data in the present study; this therefore indicated an anatomical association between neovessel formation and tumour cell proliferation. In addition, this anatomical link may be supported by the overexpression of several angiogenic cytokines, including vascular endothelial growth factor, fibroblast growth factor, thymidine phosphorylase and tryptase, which have been previously demonstrated to be present in PDAC tissue (32-35). These cytokines, secreted from tumoral and stromal cells, have a role in the autocrine and paracrine growth stimulation of tumoral and endothelial cells (36-38).

In conclusion, the data presented in the current study suggested a pre-clinical background for the future evaluation of novel therapeutic treatments, which combine angiogenesis inhibitors and anti-proliferative chemotherapeutic drugs for PDAC. The study demonstrated that in association with angiogenesis, MVD, EA and Ki-67 proliferation index, are significantly correlated to each other in PDAC tumour tissues, and were significantly increased in these tissues compared with levels in normal tissues. Following future confirmation of the data, the analyzed biomarkers may identify an integrated panel of clinical aggressiveness which may be useful in the future to select patients who are suitable to receive potential adjuvant treatment.

\section{References}

1. Folkman J: Tumor angiogenesis and tissue factor. Nat Med 2: 167-168, 1996.

2. Ranieri G, Coviello M, Chriatti A, et al: Vascular endothelial growth factor assessment in different blood fractions of gastroenterology cancer patients and healthy controls. Oncol Rep 11: 435-439, 2004.

3. Ranieri G, Labriola A, Achille G, et al: Microvessels density, mast cell density and thymidine phosphorylase expression in oral squamous carcinoma. Int J Oncol 21: 1317-1323, 2002. 
4. Ranieri G, Patruno R, Lionetti A, et al: Endothelial area and micrivascular density in a canine non-Hodgkin's lymphoma: An interspecies model of tumor angiogenesis. Leuk Lymphoma 46 : $1639-1643,2005$

5. Yamazaki K, Nagao T, Yamaguchi T, et al: Expression of basic fibroblast growth factor (FGF-2)-associated with tumour proliferation in human pancreatic carcinoma. Virchows Arch 431: 95-101, 1997.

6. Díaz VM, Planaguma J, Thomson TM, et al: Tissue plasminogen activator is required for the growth, invasion and angiogenesis of pancreatic tumor cells. Gastroenterology 122: 806-819, 2002.

7. Weidner N, Semple JP, Welch WR and Folkman J: Tumour angiogenesis and metastasis - correlation in invasive breast carcinoma. $\mathrm{N}$ Engl J Med 324: 1-8, 1991

8. Soucek L, Lawlor ER, Soto D, et al: Mast cells are required for angiogenesis and macroscopic expansion of Myc-induced pancreatic islet tumours. Nat Med 13: 1211-1218, 2007.

9. Pang B, Fan H, Zhang IY, et al: HMGA1 expression in human gliomas and its correlation with tumor proliferation, invasion and angiogenesis. J Neurooncol 106: 543-549, 2012.

10. Sharma SG, Aggarwal N, Gupta SD, et al: Angiogenesis in renal cell carcinoma: Correlation of microvessel density and microvessel area with other prognostic factors. Int Urol Nephrol 43: 125-129, 2011.

11. Sanci M,Dikis C,Inan S, et al: Immunolocalization of VEGF, VEGF receptors, EGF-R and Ki-67 in leiomyoma, cellular leiomyoma and leiomyosarcoma. Acta Histochem 113: 317-325, 2011.

12. Gravdal K,Halvorsen OJ, Haukaas SA and Akslen LA: Proliferation of immature tumor vessels is a novel marker of clinical progression in prostate cancer. Cancer Res 69: 4708-4715, 2009.

13. Koide N, Saito H, Suzuki A, et al: Clinicopathologic features and histochemical analyses of proliferative activity and angiogenesis in small cell carcinoma of the esophagus. J Gastroenterol 42: 932-938, 2007.

14. Tenderenda M: Potential prognostic value of angiogenesis, cell proliferation and metastasing in patients with surgically treated gastric cancer-current knowledge. Wiad Lek 59: 855-860, 2006 (In Polish).

15. Imamura $\mathrm{M}$, Yamamoto $\mathrm{H}$, Nakamura $\mathrm{N}$, et al: Prognostic significance of angiogenesis in gastrointestinal stromal tumor. Mod Pathol 20: 529-537, 2007.

16. Fujita S, Nagamachi S, Nishii R, et al: Relationship between cancer cell proliferation, tumour angiogenesis and 201Tl uptake in non-small cell lung cancer. Nucl Med Commun 27: 989-997, 2006

17. Chen Y, Zhang S, Chen YP and Lin JY: Increased expression of angiogenin in gastric carcinoma in correlation with tumor angiogenesis and proliferation. World J Gastroenterol 12: 5135-5139, 2006.

18. Patruno R, Zizzo N, Zito AF, et al: Microvascular density and endothelial area correlate with $\mathrm{Ki}-67$ proliferative rate in the canine non-Hodgkin's lymphoma spontaneous model. Leuk Lymphoma 47: 1138-1143, 2006.

19. Schlüter C, Duchrow M, Wohlenberg C, et al: The cell proliferation-associated antigen of antibody Ki-67: A very large, ubiquitous nuclear protein with numerous repeated elements, representing a new kind of cell cycle-maintaining protein. J Cell Biol 123: 513-522, 1993.

20. Kalogeraki A, Tzardi M, Panagiotides I, et al: MIB1 (Ki-67) expression in non-Hodgkin's lymphomas. Anticancer Res 17: 487-491, 1997.

21. Stipa F, Lucandri G, Limiti MR, et al: Angiogenesis as a prognostic indicator in pancreatic ductal adenocarcinoma. Anticancer Res 22: 445-449, 2002
22. Karademir S, Sökmen S, Terzi C, et al: Tumor angiogenesis as a prognostic predictor in pancreatic cancer. J Hepatobiliary Pancreat Surg 7: 489-495, 2000.

23. Edge SB, Byrd DR, Compton CC, et al (eds): AJCC Cancer Staging Manual. 7th Edition. Springer, New York, NY, pp241-249, 2010.

24. Hamilton SR and Aaltonen LA (eds): Pathology and Genetics. Tumours of the Digestive System. In: World Health Organization Classification of Tumours. International Agency for Research on Cancer (IARC). 3rd Edition. Volume 2. IARC Press, Lyon, France, pp1-307, 2000.

25. Ranieri G, Grammatica L, Patruno R, et al: A possible role of thymidine phosphorylase expression and 5-fluorouracil increased sensitivity in oropharyngeal cancer patients. J Cell Mol Med 11: 362-368, 2007.

26. Ranieri G, Labriola A, Achille G, et al: Microvessel density, mast cell density and thymidine phosphorylase expression in oral squamous carcinoma. Int J Oncol 21: 1317-1323, 2002.

27. Ammendola M, Sacco R, Sammarco G, et al: Mast cells positive to tryptase and C-Kit receptor expressing cells correlates with angiogenesis in gastric cancer patients surgically treated. Gastroenterol Res Pract 2013: 703163, 2013.

28. Ammendola M, Sacco R, Donato G, et al: Mast Cell positive to tryptase correlates with metastatic lymph nodes in gastrointestinal cancers patients treated surgically. Oncology 85 111-116, 2013.

29. Ma Y, Hwang RF, Logsdon CD and Ullrich SE: Dynamic mast cell-stromal cell interactions promote growth of pancreatic cancer. Cancer Res. 73: 3927-3937, 2013.

30. Wang X, Chen X, Fang J and Yang C: Overexpression of both VEGF-A and VEGF-C in gastric cancer correlates with prognosis and silencing of both is effective to inhibit cancer growth. Int J Clin Exp Pathol 6: 586-597, 2013.

31. Ammendola M, Zuccalà V, Patruno R, et al: Tryptase-positive mast cells and angiogenesis in keloids: A new post-surgical target for prevention. Updates Surg 65: 53-57, 2013.

32. Patsouras D, Papaxoinis K, Kostakis A, et al: Fibroblast activation protein and its prognostic significance in correlation with vascular endothelial growth factor in pancreatic adenocarcinoma. Mol Med Rep 11: 4585-4590, 2015.

33. Matsuda Y, Yoshimura H, Suzuki T, et al: Inhibition of fibroblast growth factor receptor 2 attenuates proliferation and invasion of pancreatic cancer. Cancer Sci 105: 1212-1219, 2014

34. Hong SP, Shin SK, Bang S, et al: Prognostic value of thymidine phosphorylase expression for pancreatic cancer. Hepatogastroenterology 56: 1178-1182, 2009.

35. Ammendola M, Sacco R, Sammarco G, Donato G, et al: Mast cells density positive to tryptase correlates with angiogenesis in pancreatic ductal adenocarcinoma patients having undergone surgery. Gastroenterol Res Pract 2014: 951957, 2014

36. Ranieri G, Mammì M, Donato Di Paola E, et al: Pazopanib a tyrosine kinase inhibitor with strong anti-angiogenetic activity: A new treatment for metastatic soft tissue sarcoma. Crit Rev Oncol Hematol 89: 322-329, 2014.

37. Humbert M, Castéran N, Letard S, et al: Masitinib combined with standard gemcitabine chemotherapy: In vitro and in vivo studies in human pancreatic tumour cell lines and ectopic mouse model. PLoS One 5: e9430, 2010.

38. Marech I, Patruno R, Zizzo N, et al: Masitinib (AB1010), from canine tumor model to human clinical development: Where we are? Crit Rev Oncol Hematol 91: 98-111, 2014. 